Sci Technol Human Values. 2010 May 1; 35(3): 330-355. doi:10.1177/0162243909340267.

\title{
National Biobanks:
}

\section{Clinical Labor, Risk Production, and the Creation of Biovalue}

\author{
Robert Mitchell \\ Duke University Catherine Waldby The University of Sydney
}

\begin{abstract}
The development of genomics has dramatically expanded the scope of genetic research, and collections of genetic biosamples have proliferated in countries with active genomics research programs. In this essay, we consider a particular kind of collection, national biobanks. National biobanks are often presented by advocates as an economic "resource" that will be used by both basic researchers and academic biologists, as well as by pharmaceutical diagnostic and clinical genomics companies. Although national biobanks have been the subject of intense interest in recent social science literature, most prior work on this topic focuses either on bioethical issues related to biobanks, such as the question of informed consent, or on the possibilities for scientific citizenship that they make possible. We emphasize, by contrast, the economic aspect of biobanks, focusing specifically on the way in which national biobanks create biovalue. Our emphasis on the economic aspect of biobanks allows us to recognize the importance of what we call clinical labor-that is, the regularized, embodied work that members of the national population are expected to perform in their role as biobank participants-in the creation of biovalue through biobanks. Moreover, it allows us to understand how the technical way in which national biobanks link clinical labor to databases alters both medical and popular understandings of risk for common diseases and conditions.
\end{abstract}

\section{Keywords}

biobank; clinical labor; database; risk; biovalue

\begin{abstract}
The development of genomics has dramatically expanded the scope of genetic research. From the 1950s to 1980s, genetic research used a range of clinical and laboratory methods-family history, cytological, and biochemical studies - to understand the links between disease and genetics. Studies were generally oriented toward rare, monogenetic diseases such as Huntington's disease or muscular dystrophy, and emphasized family-based studies (CambonThomsen et al. 2003). Genomics involves the application of information technology to genetic analysis and develops the informatics approach to molecular biology exemplified by the Human Genome Project (HGP). The HGP, which sequenced a representative form of the human genome and published it in the public domain, did not provide any knowledge of genetic variability between populations, nor did it provide any analysis of the relationship between genes and disease. Genomics-high-throughput genetic analytic techniques-are currently being developed and applied to study these aspects of biology. Although clinical genetics is focused on monogenetic disease, with a relatively simple understanding of the relationship between genetic mutation and illness, genomics approaches can analyze far more data. Hence, genomics researchers hope to study much more complex interactions between clusters of
\end{abstract}

\footnotetext{
(c) SAGE Publications.

Declaration of Conflicting Interests

The authors declared no conflicts of interest with respect to the authorship and/or publication of this article.
} 
genetic variation, environmental and lifestyle factors, and the etiology of more common diseases, such as Alzheimer's, diabetes, and cancers. Genomics companies, which sequence and sell genetic information, pharmaceutical companies, which seek to apply high-throughput approaches to drug design, and academic researchers interested in basic biology are all using genomic technologies to pursue their interests.

Researchers require access to systematic collections of human biological materials to provide the genetic raw material for genomic analysis, and collections of genetic biosamples have proliferated in countries with active genomics research programs. Since the 1990s, various forms of corporate genetic collections have proliferated. Pharmaceutical companies have developed in-house DNA collections, taking blood samples from participants in clinical drug trials. The contract research organizations (CROs) that undertake clinical trials for pharmaceutical companies routinely have both tissue archiving and genetic research capacity (Lewis 2004). As Gibbons and colleagues have noted, research collections have proliferated in the United Kingdom, the second-largest player (after the United States) in genetic research, and "range from relatively small scale, family-based collections ... all the way up to populationbased collections involving several hundreds of thousands or millions of individuals, established primarily and explicitly for carrying out genetic epidemiology" (2007, 167-8).

Our concern in this article is with a particular kind of collection, national biobanks. Since the late 1990s, a number of countries have established nationally delimited, population-based genetic databases, more commonly known as population biobanks. Iceland was the first state to attempt to create such an explicitly national biobank, the Icelandic Health Sector Database, as distinct from the heterogeneous tissue collections accumulated over many years by hospitals, universities, and commercial research organizations. ${ }^{i}$ Several countries have followed suit, including Estonia, Japan, Sweden, Singapore, the United Kingdom, and Austria, and many others are at the advanced planning stage, including Taiwan and Australia. Most are funded as some form of public/private partnership, with money coming from national research councils, medical charities, biotech venture capital, and pharmaceutical company investment (Lewis 2004). Some, such as the UK Biobank, are positioned as nonprofit, public domain institutions, whereas others have been conceived as for-profit endeavors; in the case of the Icelandic biobanking efforts, for example, a private company, deCODE Genetics, was granted exclusive license to commercialize the data.

The scientific rationale for such large, population-based collections is the complexity of genetic contribution to common diseases and of the gene-environment interactions. ${ }^{\text {ii }}$ Population biobanks, with biosample contributions from hundreds of thousands of individuals, will, researchers hope, provide the statistical power necessary to identify the relatively weak contribution of clusters of small genetic polymorphisms to disease, and the effects they may have on risk factors and drug action. Yet, to probe gene-environment interactions, population biobanks also require relatively long-term access to information about donors, such as health records, lifestyle, and so on. In some cases, there has been an effort to link biobanks databases to national health records, and biobank donors may have extensive medical examinations and interviews on donation. Access to retrospective and prospective health data allows researchers

\footnotetext{
${ }^{1}$ The current status of the Icelandic Health Sector Database is unclear, though the chance that it will be completed now seems slight (Rose 2006).

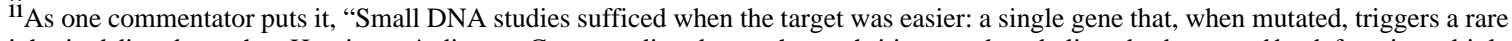
inherited disorder such as Huntington's disease. Common disorders such as arthritis or stroke-believed to be caused by defects in multiple genes in combination with lifestyle factors such as diet and smoking - pose a trickier challenge. Because each gene contributes just a small amount to overall risk, it emits a weaker signal, confounding efforts to find it. To compensate, researchers need to study genetic profiles of many more people and also incorporate information on phenotype or health data" (Kaiser 2002, 1158). Although most largescale national biobanks developed or proposed to date have emphasized the importance of genetic data, it is worth emphasizing that many of these same biobanks could also be used for other kinds of -omics, such as proteomics or metabolomics, which are of increasing interest to clinical researchers.
} 
to test out relationships between gene expression and drug response, for example, and is a central feature of biobank design. Population biobanks are thus technologies that mediate between genetic information, biological samples, and patient experience on one hand, and between nation-states, populations, and "big science" on the other. .ii $^{\text {. }}$

As Cambon-Thomsen and colleagues note, once biobanking becomes a national project, rather than a series of fragmented commercial or university-based collections, it also becomes "a matter of scientific political decision at the level of national resource exploitation" (CambonThomsen et al. 2003, 629). The resource itself requires sometimes extensive involvement of significant proportions of the national population, immediately raising issues of citizenship and the role of the state in the mobilization of citizen participation. The term "resource" is telling here, because it points toward the economic role of national biobanks. Although such biobanks will be used extensively by basic researchers, they will also form a primary research site for pharmaceutical, diagnostic, and clinical genomics companies (Lewis 2004) seeking to develop profitable therapeutics and predictive tests. Moreover, today, the basic, public sector research carried out in universities and institutes is likely to be sponsored by industry partners, who often fund basic biology laboratories.

In this respect, population biobanks are set to become important research resources in the global bioeconomy. ${ }^{\text {iv } 4}$ The bioeconomy, or at least its biomedical aspect, is based on human tissue fragments, which can be analyzed, reformulated, and altered in vitro to make them biovaluable, to yield surpluses of both profit and health, often through the transformation of tissues and information into commodities (Waldby 2002;Waldby and Mitchell 2006). If a viable medical bioeconomy is to be built, medical researchers require proprietary control of high volumes of human tissue, which must be voluntarily donated. In the case of biobanks, tissues must be donated by significant sectors of the population. Population biobanks thus raise compelling questions about contemporary biopolitics — what do they tell us, for example, about emerging relationships between populations, nation-states, and biocapital (Rajan 2006)? What kind of value is generated from donor involvement and what are the biopolitical interests driving biobank formation? What are the likely effects of biobank research on population health and on our understandings of health and illness more generally?

Although national biobanks have been the subject of intense interest in recent social science literature, most work on this topic has focused on either bioethical issues related to biobanks, such as the question of informed consent, or the possibilities for scientific citizenship that they make possible. In this essay, by contrast, we emphasize the economic aspect of biobanks, focusing specifically on the way in which national biobanks create biovalue. Our analysis of the economic dimension of national biobanks is based primarily on publicly available information provided by biobanks themselves, though we have also drawn on pharmaceutical industry reports concerning the future of DNA-based diagnostics. We suggest that our emphasis on the economic aspect of biobanks provides us with a new theoretical approach to biobanks by allowing us to recognize the importance of what we call clinical labor-that is, the regularized, embodied work that members of the national population are expected to perform in their role as biobank participants-in the creation of biovalue through biobanks. Moreover, it allows us to understand how the technical way in which national biobanks link

\footnotetext{
iii We use the term "big science" to refer to the kinds of large-scale platform research that exceed the capacities of any particular laboratory or corporation but which nevertheless advances scientific practice across the board. The HGP, which was conducted by an international consortium and which received substantial amounts of public funding, is an example of big science.

${ }^{1 \mathrm{~V}}$ The global economy is defined by the Organization for Economic Cooperation and Development (OECD) as, "The aggregate set of economic operations in a society that use the latent value incumbent in biological products and processes to capture new growth and welfare benefits for citizens and nations .... The bioeconomy is made possible by the recent and continuing surge in the scientific knowledge and technical competences that can be directed to harness biological processes for practical applications. Looking to the future, new techniques in biotechnology, genomics, genetics, and proteomics will continue to converge with other technologies resulting in potentially large-scale changes to global economies in the next thirty years" $(2006,1)$.
} 
clinical labor to databases alter both medical and popular understandings of risk for common diseases. We argue that national biobank research, at least as currently configured as a "partnership" between national polities and biomedical corporations, will both multiply risk categories for disease and expand the scope of risk, defining more and more people as being at risk for future illness and in need of testing and medication. The logic of risk expansion reverses the logic of many other forms of biovalue creation, which operate by severing all relations of identity and possession between donor and tissue fragment (Waldby and Mitchell 2006), though, as we note in our conclusion, these two forms of biovalue creation can nevertheless operate in tandem.

\section{Scientific Citizenship and the Population as Resource}

The current literature exploring relationships between donor populations and biobanks is of two main types. One is a legal and bioethical literature addressed to issues of privacy, confidentiality, consent, and regulation, which is concerned to protect donor populations from unwarranted use of their genetic information and to ensure appropriate forms of regulation (Hyman, 1999; Austin, Harding, and McElroy 2003; DeCamp and Sugarman 2004). So, for example, Gibbons and colleagues are concerned that the legal regulation of biobanks in the United Kingdom is "highly complex, confusing, uncoordinated, and inadequate" (2007) and that far more regulatory work is required to adequately address all the legal issues around consent, ownership of samples, and the jurisdictions of governing bodies. The second literature is sociological and explores the implications of population involvement for citizenshiprevolving around issues of trust and legitimacy, the conditions of civil participation, citizen rights, democratic science, and the power of public participation to shape the biobanks effort (Levitt and Weldon 2005; Salter and Jones 2005; Petersen 2005; Busby and Martin 2006; Tutton 2007). Broadly speaking, the rights and duties of the scientific citizen are used in this literature as a normative device for assessing the claims to public good and ethical governance made by the biobanks. So, for example, the assessment of public perceptions of the UK Biobank $\mathrm{V}^{\mathrm{V}}$ by Levitt and Weldon concludes that potential participants were unconvinced by assurances of the bank's devotion to public good and privacy protection:

The expert agenda of policy-makers and medical ethics does not address the broader concerns expressed by participants. It seems that public consultation and the language of openness and transparency may not be sufficient to establish trust in the governance of genetic databases. Donors will be asked to give freely without any return but the participants' perception of those using the samples is that they are motivated by success and profit rather than healthcare priorities. In this context altruism seems naive and even dangerous. In order to place their trust well people need evidence of a relationship with obligations and expectations on both sides (Levitt and Weldon 2005, 311).

In other words, biobanks should be held to public account in terms of their claims to further the collective interests of their donors and the public interests of the citizens more generally.

This citizenship approach derives its coherence and traction from the explicit affiliation between population biobanks and the nation-state. National biobanks-the Estonian biobank, the UK Biobank, the Icelandic Health Sector Database-evoke the social contract between citizens and government, a relationship strengthened by public funding and parliamentary endorsement. The legitimacy of the state is an essential dynamic in mobilizing population

\footnotetext{
${ }^{\mathrm{v}}$ The UK Biobank has been planned since 2001 and is now in full operation. It aims to enroll 500,000 people from all around the United Kingdom who are currently aged fourty to sixty-nine. It is considered one of the most ambitious biobanks because it is being built de novo, rather than building on existing tissue collections and epidemiology studies. It is being funded primarily by the Medical Research Council and the Wellcome Trust.
} 
involvement, and states are generally careful to stress the public oversight they will provide to the national biobanks in order to protect citizens' rights and and to contain the commercial aspects of the project. So, for example, the Swedish biobank is built on an extant public collection of blood samples donated since the 1950s to the Vasterbotten medical biobank for research on cardiac disease. In 1999, in an attempt to "add value" to this collection, the Swedish government gave commercialization rights to a private genomics company, UmanGenomics. Incipient public controversy was dampened by bringing the company under public oversight (state and university shareholders own over 50 percent of the company) to reassure donors that the Swedish state was still in control of the project, and hence that it was still organized in the interest of the national community (Hoeyer 2004).

However, we consider that characterizing population involvement in biobanks primarily in civil terms makes it difficult to analyze the economic role played by populations. Along with Lewis (2004), we position national biobanks as one form of genetic research facility among many and see considerable continuity between national biobanks and commercial biobanks. As Rose notes, the move to biobanking is part of a more general move by states, and also by venture capital and pharmaceutical companies, toward predictive medicine and pharmacogenetics (Rose 2001). Genomic research promises to deliver population health benefits and commercial returns, national scientific prestige as well as global economic competitiveness. In other words, donor participation in biobanks contributes simultaneously to state and pharmaceutical interests, public and private value. The existing citizenship literature, however, tends to interpret the role of biocapital in biobanks as a queering of the properly democratic aims of biobanks and a distorter of public participation.

\section{Biovalue and Clinical Labor}

To broaden debate and focus attention on the commercial aspects of national biobanks, we want to explore the economic role played by donor populations in the creation of biovalue. The term biovalue refers to the yield of both vitality and profitability produced by the biotechnical reformulation of living processes. In vitro tissues can be technically altered to make them productive in a variety of ways, for example, transformed into cell lines, genetic sequences, or genetically modified organisms that can be used in the generation of both health and commercial returns (Waldby 2002; Waldby and Mitchell 2006). The production of biovalue is central to the development of bioeconomies. The citizenship status of donor populations is important in understanding this role; but in our analysis, a clear opposition cannot be made between public, civil participation, and the constitution of a population as a bioeconomic "resource." As Ong argues, a feature of contemporary neoliberal governance is the marketization of citizenship and the articulation of civil rights and obligations with economic demands:

A focus on neoliberalism recasts our thinking about the connection between government and citizenship as a strictly juridical legal [sic] relationship. [Neoliberal states use] a biopolitical mode of governing that centers on the capacity and potential of individuals and the population as living resources that may be harnessed and managed by governing regimes .... The elements we think of as coming together to create citizenship —rights, entitlements, territoriality, a nation—are becoming disarticulated and rearticulated with forces set in motion by market forces $(2006,6)$.

The importance of biovalue for national biobanks has not been immediately evident, for in many ways, popular participation in national biobanks resembles participation in older epidemiological prospective studies. As Corrigan (2006) notes, for example, the UK Biobank, a prospective cohort study, builds on a British history of prospective cohort studies such as the 1958 National Child Development Study (NCDS), which included 17,000 births, various follow-up studies, and a battery of tests. Furthermore, a number of national biobanks, for 
example, the Swedish biobank and the Genome-Austria biobank, are building on extant epidemiology collections, augmenting them in various ways with current biosamples, new donors, and linkages with national medical records.

These earlier large-scale epidemiology studies in both Europe and the United States during the mid-twentieth century were strongly linked with the idea of national public health and with the administration of a discreet national population. Epidemiological studies were understood to render population-level processes of health visible to medical researchers, statisticians, and health educators and to designate forms of intervention to improve child nutrition, cardiac disease prevention, vaccination levels, and so on. So, for example, the long-running Framingham Heart Study (FHS) in the United States-a study of multiple generations of several thousand medically "representative" Americans living in the town Framingham, Massachusetts-was understood to facilitate public health by generating information about the causes of heart disease. One of the results of this study was the introduction of the concept of "risk factor" into medical research (Levy and Brink 2005, 282-85; Rothstein 2003) as well as the formulation of a number of specific risk factors for heart disease, and information about these risk factors was used to inform individual lifestyle choices about, for example, food consumption patterns and exercise habits.

National biobanks have similar population health aims-to discern the etiology of common illnesses - but the forms of research that they enable are strongly linked to various types of pharmaceutical and diagnostic biocapital. Where older prospective cohort studies were understood to facilitate the public good by generating information on which individuals could draw in making lifestyle choices-information, for example, about the contributions of smoking or exercise to the risk of heart disease-national biobanks almost invariably present the path from biobank to public good as one that leads through the commercial creation of profitable drugs and diagnostic tools. This is because national biobanks lend themselves in very direct ways to the research needs of the pharmaceutical industry. As Rajan notes, pharmaceutical companies are keen supporters of public domain genomic research, because most companies are users rather than generators of genomic data. In the absence of public genomic research, these companies must pay licence fees to private genomics sequence companies. "Therefore, even public/private debates are overcoded by corporate fights" (2006, 45). Furthermore, genomic research lends itself more easily to the development of diagnostic technologies and to pharmacokinetic studies (how different bodies metabolize drugs) than it does to basic etiological studies (Rajan 2006), tipping biobank genomics further toward corporate uses.

So, if we examine the kinds of health promised by the national biobanks, we find that it is, generally speaking, skewed toward diagnostic testing and medication. deCODE, for example, emphasizes its commitment "to develop drugs and diagnostics," and cites the development of a diagnostic 1 test and preventive therapies for heart attack and arterial thrombosis as evidence of success; BioBank Japan is "expected to be able to develop new diagnostic methods and innovative drugs diagnostic methods and innovative drugs" as well as possibilities for "personalized medicine ... where the treatment is tailored to the individual ... for example, through different drug treatments for different patients with the same diagnosis or similar symptoms, on the basis of subtle differences in each patient"; whereas in the United States, the need for a national biobank "network" has been supported with the claim that the development of the cancer drugs Herceptin and Gleevec highlights the possibilities afforded by biobanks in the discovery of therapies. ${ }^{\mathrm{vi}}$ In keeping with a public good logic most clearly articulated in the

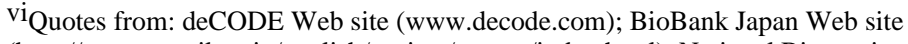
(http://www.src.riken.jp/english/project/person/index.html); National Biospecimen Network Blueprint (Friede et al. 2003, 1). Web sites accessed on September 27, 2008.
} 
United States in the 1980s in Bayh-Dole legislation (Waldby and Mitchell 2006), and subsequently "exported" via international trade agreements such as the World Trade Organization's Agreement on Trade-Related Aspects of Intellectual Property Rights (TRIPS), national biobanks are generally premised on the belief that the public good will be facilitated by commercial innovation of preventive, therapeutic, and diagnostic agents and tests. ${ }^{\mathrm{vii}} \mathrm{As}$ a consequence, biomedical for-profit corporations have been consistently included among the "stakeholders" whose interests must be addressed in decisions about biobanking.viii

Insofar as the viability of national biobanks is premised on a link between public resource and private commercialization, we propose to describe the participation of donors as a kind of clinical labor, a form of embodied biomedical work that produces economic value. Following the analysis by Waldby and Cooper (2008), we use the term "clinical labor" to refer to processes in which subjects give clinics and commercial biomedical institutions access to their in vivo and in vitro biology, the biological productivity of living tissues within and outside their bodies. Research subjects might provide the living materials that are the primary resources for various forms of biovaluable production, such as women who donate embryos or cord blood for stem cell research. In more onerous forms of clinical labor, research subjects may become clinical trial participants, lending their bodily metabolism and everyday experience of health and illness to often risky pharmaceutical research (Cooper 2008), or they may work as oocyte vendors, selling their fertile oocytes to infertile couples (Waldby 2008). Clinical labor also involves second-order tasks, such as compliance with often-complex medical regimes of dosing, testing, appointments, and self-monitoring, because a noncompliant population can render reproductive and clinical procedures useless (Nahman 2005).

Unlike clinical trial participation or the selling of oocytes, which are intensive forms of clinical labor, involving the prolonged endurance of risk and discomfort, participation in biobanks is a highly distributed and extensive form of labor. That is, a relatively small amount of productive work is allocated across many participants, because biobanks require such large population samples to gain statistical power. The need for large numbers of participants necessitates that recruitment clinics can ask for only limited direct access to the bodies of participants. Recruitment may involve travel to the recruitment center, answering one or several health questionnaires, cooperating in baseline clinical and biometric studies (e.g., blood pressure and body mass index [BMI] calculations), and donation of blood, urine, and/or other tissue. Participants also give their consent to the biobank to access their various medical records (general practice records, hospital admissions, cancer registries) for the duration of participation, which might be for twenty or thirty years. In the case of the UK Biobank, for example, the recruitment process is estimated to take between ninety minutes and two hours.

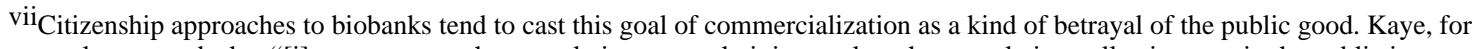
example, contends that "[i]n contrast to other population research, it is not clear that population collections are in the public interest .. the primary aim of most commercial research is not to promote the health of society, but to develop research plans that will bring in profits for shareholders and investors. The values that are implicit in a medical research culture located within a national health system do not have primacy in the context of a population biobank .... While it is anticipated that there will be long-term benefits to humanity as a whole from conducting research in population collections, many of the short-term benefits, such as intellectual property rights and profits will flow to the private company involved" (2004, 125-6). Although we agree with Kaye's basic sentiments, our economic analysis is designed to focus more attention on the ways in which clinical labor has been incorporated into the practices and institutions that generate those "short-term" benefits of intellectual property rights and profits.

viii See, for example, the minutes of the April 2003 "U.K. Biobank Consultation With Industry Workshop," in which industry is positioned as among the stakeholders in the U.K. Biobank, and one, moreover, with a "special role ... in certain areas of biomedical science" (http://www.ukbiobank.ac.uk/docs/Industry_Workshop.pdf; accessed September 27, 2008). In the context of discussions of biobanking, the concept of "stakeholders" has encouraged the sense that for-profit businesses have rights and moral claims that must be respected by government entities, nonprofits, and other actors (e.g., physicians). There is some irony in this fact, because the concept originated in business theory as an attempt to broaden, beyond the class of shareholders, those groups to which a corporation understood itself as responsible (Freeman 1984). However, when the concept was subsequently applied outside a corporation-specific context—as in, for example, Tony Blair's 1996 call for Britons to work toward a "stakeholder economy" (Davies 1996) and related discussions of the "stakeholder society" (Hutton and Goldblatt 1999)—it became possible for corporations (as well as many bioethicists) to describe for-profit corporations as "stakeholders" whose interests ought to be consulted in the use of government monies and projects.
} 
A proportion of participants will be followed up via e-mail each year to provide self-reports on their health, prescription drug use, and so on (Anon 2006).

In addition to this direct in vivo access, participants give ongoing access to their tissue samples and prospective medical histories. This secondary access does not involve their presence but rather tracks interactions between their genetic constitution and their embodied life through the biosample and the health record. As with all large-scale biological collections, the tissue sample acts as a proxy for the donor, a more manageable, processable material than the whole organism, and in turn genetic information (e.g., single nucleotide polymorphisms [SNPs] and haplotypes) acts as a proxy for the tissue (Parry 2004). The interactions between biosamples and genetic information will be explored in the next section. However, what we want to stress here is that biosamples and informatics data are not treated as exhaustive proxies for the organism in biobanks, and this is why the database must mediate between sample, DNA information, and the unfolding medical history of the donor.

In this way, the everyday biological life of the participant remains locked in a productive relation with the biobank, and the apparently private world of health, illness, patient experience, and mortality can be enrolled in new circuits of biovaluable productivity. The enrolled population and its collective history of disease form a resource that can be data mined, in the same way that database marketing businesses mine the everyday world of consumption patterns - of, for example, book or grocery purchases - for information that can then be sold on to other companies (Taylor 2004). (deCODE, e.g., has created a 'DiseaseMiner' software package which 'scans through large databases and finds correlations between diseases and genes' [FujiKeizai U.S.A. 2008, 73].) Population biobanks, moreover, have a cumulative logic. Each additional participant and his or her medical history add value to the overall collection both synchronically and diachronically. Synchronically, they add to the validity of analysis. Each additional case adds to the strength of claims that can be made about the research, the likelihood that a relationship between clusters of genes and disease events can be demonstrated. Each additional case also adds to the usefulness of the resource for more research projects. In diachronic terms, the longer the period of participation of a given patient, the more valuable the data produced by the biobank. The biobank tracks the accumulation of morbidity and mortality in its generational cohorts, as they move through aging and death. The data only become valuable as large numbers of cases of particular disease develop among its participants, creating enough statistical power for genomic studies to be meaningful. Beyond the lifetime of participants, the biological samples themselves can be retained and repeatedly mined for a variety of research. Hence, the database is potentially open to new techniques, methods, and research questions that develop in the future.

Biobank planners and managers naturally have been reluctant to describe the activities of biobanking participants as a kind of labor, preferring instead to describe these activities as "gifts" or modes of "sharing," while at the same stressing that intellectual property rights in the tissues and data belong to the bank alone (Petersen 2005). It might seem as well that without the formatting of samples and data provided by the biobank, no value would be constituted. However, our point is that a biobanks participant must also format his or her activities in ways demanded by the biobanks, even if only in the simple sense of remaining within the health care system to which the biobank is linked and providing answers about lifestyle and environmental exposures in formats that can be processed by the biobank. Both biobank managers and biobank participants are involved in formatting the data necessary for the bank's creation of value, but to date, biobank managers have preferred to attribute the creation of biobank value only to the activities of the former. 


\section{Biovalue and the Logic of the Database}

To make use of the distributed, extensive form of clinical labor on which national biobanks are based, these institutions require very large numbers of participants to constitute a viable genomic research facility. The UK Biobank, for example, aims to include 500,000 subjects; deCODE includes 100,000 subjects; the Estonian Genome Project aims to include 100,000; and Collins has called repeatedly for the establishment of a 500,000-subject biobank in the United States (Collins 2004, 2007). This scale is in part a function of the "prospective" nature of these biobanks. In contrast to case-control studies, in which data are gathered on individuals who have already manifested a disease (as well as healthy controls), prospective studies seek to gather clinical and environmental data before subjects manifest illnesses. Most health outcomes of interest will only affect a small fraction of the population, and thus a biobanks must begin with a very large population, if it is to investigate successfully conditions that are rare. As we described above, the banks continue, whenever possible, to collect data during the development of diseases. Proponents of national biobanks have stressed, accurately, that environmental data gathered prospectively are much more useful and accurate than data based on patient memories of environmental exposures that occurred prior to the start of a casecontrol study (Collins 2004, 476). In general, then, prospective studies must include many more subjects than they might seem to "need," because researchers cannot know in advance which of their subjects will develop a disease, and only a small fraction of them will develop any given disease.

Another reason that national biobanks must be large is that they are not designed to focus on particular health problems that are specified in advance but are instead designed to serve as a platform for multiple specific, focused studies (many of which may then take the form of casecontrol studies). In contrast to earlier prospective studies such as the FHS, the NCDS, or National Health and Nutrition Examination Survey (NHANES), which were designed to focus on a specific kind of illness or environmental impact (heart disease, children's health, and nutrition, respectively), national biobanks are designed to be "all purpose," facilitating the study of multiple diseases. They thus require far larger numbers than more focused prospective studies simply to ensure that a sufficient number of people will be statistically likely to develop multiple diseases of interest.

The extremely large number of subjects at which national biobanks are aiming is also driven by the decision to include genomic data in these projects. It is worth stressing that the inclusion of genomic data is by no means a necessary component for an open-ended prospective cohort study (and some critics have argued that information derived from nongenomic studies would be of equal or greater public health benefit than data derived from studies that seek to ascertain gene-environment interactions). ${ }^{\mathrm{ix}} \mathrm{We}$ discuss the economic logic that encourages national polities to focus on gene-environment interactions below, but in this section, our point is that the decision to include genomic data has a direct effect on the scale of biobanks, because in addition to health outcomes and environmental exposures, biobanks must capture a large enough fraction of the population to represent the full range of genetic diversity in it. The purpose of including genomic data is to make correlations between environmental factors, genetic differences (both before and during onset of disease), and incidence of disease. To make such correlations, researchers use "biomarkers" that allow them to register small differences - often at the level of base pairs variations, rather than genes of known functionbetween the genotypes of different individuals. Because biomarkers can generally be taken as proxies for differences in genes or regulatory functions, they allow researchers to focus on

\footnotetext{
${ }^{i x}$ So, for example, Smith and colleagues contend that "[o]verall reduction in disease burden based on population intervention irrespective of genotype will generally be more substantial than intervention targeted according to genotype" (Smith et al. 2005, 1488). (In support of their claims, Smith et al. 2005, citing Khoury et al. 2004.)
} 
biomarker differences even without knowing precisely how these small genetic differences are themselves causally related to phenotypical differences. Moreover, in their function as proxies, biomarkers allow researchers to avoid sequencing the entire genome of each individual, which would be expensive and time-consuming (and in most, if not all, cases, biomarker proxies would be as accurate as full sequences). Nevertheless, the large number of available useful biomarkers - in the case of SNPs, for example, there are already more than three million potential markers in humans-require that studies be carried out in large subject populations, so that statistically useful differences can be observed. ${ }^{\mathrm{X}}$ The architects of the U.K. Biobank estimate that they need at least 500,000 subjects to ensure an incidence of 5-10,000 cases of diseases of interest, with this latter number understood as an incidence sufficient not simply for study of environmental factors but for study of environmental factors in combination with genome-wide association analyses (Anon 2006).

The need for such large subject populations favors national polities over commercial entities as the primary site of biobank creation. National polities are far more likely than commercial entities to have the resources for soliciting the participation of such large numbers of people, and it is questionable whether any commercial entity would be willing to commit such financial resources to what is, at present, an unproven "resource." A nationally coordinated effort is also more likely than isolated smaller studies to create data field uniformity. The need for overall data field uniformity is again a function of the genomic aspect. Although one can link the results of smaller prospective cohort studies that focus on environmental exposure into more general prescriptions for health, the desire to link an analysis of environmental effects to genomic analysis requires that data fields for environmental effects be standardized. However, as Collins has noted,

[p]henotypic measures used by the existing cohorts, although standardized within cohorts, have not followed uniform procedures across studies, and so there will be significant challenges to merging data from different studies in a valid way. Moreover, key environmental exposures or risk factors will also certainly differ systematically across cohorts (Collins 2007, 259).

As Collins stresses, data field standardization is difficult, if not impossible, to achieve "after the fact": such as their subjects, individual biobanks themselves tend to be "idiomatic," in the sense that every bank must choose the aspects of individual health biographies that are to be measured. It is thus in practice very difficult, if not impossible, simply to link existing smaller biobanks together because they do not gather the same data in the same formats; rather, data fields must be standardized at the start of a study. The problem is not that different groups store the same information in different ways; rather, the problem is that different groups are interested in different kinds of information, and the study "frame" cannot be warped once it has been built. Although there may be some common data fields-for example, mortalitythis minimal consensus is not enough to produce the rich annotation that is necessary to create a valuable national biobank resource. The requirement of data uniformity thus also favors national health systems that consistently gather information about entire populations. ${ }^{\mathrm{xi}}$

\section{Population Genomics and Risk Expansion}

In establishing large-scale platforms for the study of gene-environment interactions, national biobanks encourage a certain kind of genetic analysis, one focused less on the genetic causes

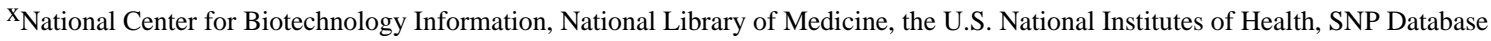
(dbSNP): http://www.ncbi.nlm.nih.gov/projects/SNP/snp_summary.cgi (accessed September 27, 2008).

${ }^{\mathrm{xi}}$ Thus, despite the enormous number of biospecimens currently banked in the United States—a 1999 study estimated "more than 307 million tissue specimens from more than 170 million cases are stored in the United States, accumulating at a rate of more than 20 million per year" (Eiseman and Haga 1999, xvii)—attempts to create a national biobank network have essentially stalled because of the "idiomatic" nature of the individual biobanks that were to be linked.
} 
of disease than on risk factors for disease. As we detail below, this has important consequences for understanding the connection between clinical labor, biovalue, and the expansion of risk factors.

Genomic information can be linked to disease states through two different paradigms. Researchers can either use combinations of clinical and genomic data to search for specific genes that cause a disease or they can search for links between genetic profiles and environmental factors that affect the probability that an individual will get a disease (Terwilliger and Go"ring 2002). The former approach is possible for only a relatively small number of "Mendelian" hereditary diseases, such as cystic fibrosis, or for cases in which specific genes are known, or believed, to cause a disease, such as "oncogenes" that cause (or suppress) cancer. In the case of a Mendelian disease, researchers generally identify genetic causes by recruiting families afflicted with the disease and then use a series of genomic biomarker scans to narrow down further and further the location of a gene that causes the disease. In the case of oncogenes, researchers can scan DNA extracted from tumor biospecimens for the presence of known or suspected oncogenes. The breast cancer drug herceptin was the result of such a search for genetic causes: in the early 1980s, Axel Ullrich, a researcher at Genentech, sent a series of isolated oncogenes to Dennis Slamon, a University of California, Los Angeles (UCLA) physician and cancer researcher who had collected a number of tumors from cancerous patients. Slamon searched DNA extracted from these tumors for the presence of the oncogenes he had received from Ullrich, and this search resulted in one "hit"- the erbB2 receptor-that was highly "overexpressed," meaning it was produced in much larger amounts on the cell surface in cancer cells compared to noncancerous cells. This key insight then allowed Genentech to begin searching for drugs that inhibited the action of the protein produced by that one gene (Slamon et al. 1989; Bazell 1998).

Large-scale population biobanks can be used to search for these kinds of causal links between genes and diseases. However, they are, in general, less efficient tools for this sort of discovery than smaller and more focused familial, case-control studies, or disease-specific studies and biobanks in which environmental exposure factors play little, if any, role. Large-scale population biobanks, by contrast, are more suited to a different kind of discovery-namely, the discovery of risk factors. The discovery of gene-environment risk factors also depends on the use of biomarkers, such as microsatellites or haplotype markers, to conduct genome-wide scans to isolate genetic points of interest. However, in the case of large-scale population biobanks, genetic points of interest are generated by linking individuals with diseases to both their genetic profiles and their environmental exposures. Such a linkage identifies not the genetic cause of a disease but rather a mere association: that is, given a specific genetic profile, an individual has a certain risk, in the presence of environmental factors, of developing a disease. In some cases, this genetic risk factor may indeed be linked to a specific gene: for example, women who have both a specific gene mutation and use oral contraceptives have a much higher risk of venous thrombosis than women with either none or only one of the risk factors (Clayton and McKeigue 2001, 1357, citing Vandenbroucke et al. 1994). However, risk factors can simply be linked to SNPs without needing to locate a specific gene, because the point is to distinguish, for a specific environmental factor, "high-risk" from "low-risk" genotypes (Clayton and McKeigue 2001). Risk factors are intrinsically relational categories, and the discernment of high- and low-risk genotypes requires a population-level analysis. As Rajan astutely notes about the use of SNPs as biomarkers, "SNPs are not about the simple correlation of a mutation to its phenotype: they are about variations in genomes, rather than differences in genes" $(2006,182)$, and the use of such biomarkers facilitates a mode of "analysis that can only be undertaken when the nucleotide is set in the context of whole populations" $(2006,163)$. Thus, in their emphasis on large-scale subject populations, national biobanks implicitly valorize the generation of genetic risk profiles over other kinds of 
epidemiological information, such as causal pathways, specific candidate genes, or nongenetic risk factors.

Insofar as national biobanks emphasize the discovery of risk factors, they tend to reverse the logic of most forms of biovalue creation. In the past, biovalue has often been produced by separating individuals from the products of their clinical labor. In the case of clinical trials, for example, though the specific biological products and health biographies of clinical trial participants are of importance during the trial itself, the trial is designed to produce information that can be generalized, and in this sense can be distinguished from the specific clinical labor that, and the clinical trial participants who, helped to generate this information. Or, to take another case, a cell line made from human tissue can be used by researchers with little, if any, knowledge about the particular body from which the tissue was derived. The economic value of the cell line, moreover, has (at least in the United States) been deemed dependent on the absence of any link to its "idiomatic" origin in a particular individual. It is only when a tissue sample is legally separated from the donor through the informed consent process, deemed no longer "his" or "hers," that it becomes biovaluable, able to be anonymized, technically altered, and claimed as the intellectual property of the scientist or corporation (Waldby and Mitchell 2006).

However, the situation is both reversed and significantly complicated in the case of the tissues and genetic information that constitute biobanks and registries. In the context of a national biobank, the use of banked or registered tissues, fluids, or genetic information is dependent on the fact that these remain linked to the particular individuals from which they were derived. Moreover, the value of such tissues increases to the extent that further information about the individual, such as new health problems and health-related behaviors, can be linked to these biospecimens. At the same time, the clinical labor on which biobanks depend requires the continued participation of populations, rather than relying on the clinical labor of isolated individuals or small groups of individuals who manifest specific health profiles (as in the case of clinical trials), possess "anomalous" tissue (as in the case of cell lines), or live in economic disadvantage (as is often the case with oocyte harvesting or third world organ transplantation). Unlike these other forms of biovalue, many uses of national biobanks depend on the persistence of links between individuals, biospecimens, and data.

Rather than understanding the persistence of this link between subjects and biobanks as simply a technical necessity, we suggest that it is also central to the ways in which biobanks effectively establish markets grounded in "risk." Prospective cohort studies are, by their nature, oriented toward the illumination of risk categories, but by collecting, and emphasizing the importance of, genetic information, national biobanks "ontologize" risk categories, linking risk not simply to behaviour but also to an ontological component of the individual (his or her genotype). This is, moreover, an ontological component that is accessible only through the mediation of technical diagnostic devices. Although an individual may be —or can easily become-aware of his or her own patterns of food consumption, he or she cannot, without the benefit of a diagnostic test, tell whether he or she has a genotype that is more likely to interact with food consumption patterns in a way that will produce obesity. Ontologizing risk thus opens up a market for diagnostic devices that will allow individuals to determine whether they are at risk for given conditions, given the presence of certain environmental exposures.

Both industry analyses of the market for DNA-based diagnostics and recent direct-to-consumer offerings of "personal genomics" services highlight the growing importance of this market for risk factor diagnostic products. A recent industry report, for example, estimates the 2008 value of all the U.S. DNA-based diagnostic tests at between US\$2.2 and US\$2.5 billion. Although the market for predisposition/risk assessment tests for chronic diseases is currently a relatively small subsection of that total market value (US\$33.6 million), the report also estimates that 
"[p]redictive screening for chronic diseases like diabetes and heart disease is an untapped market opportunity set to rise rapidly (250 percent)" (Fuji-Keizai U.S.A. 2008, 11, 15). Evidence of this growing market is provided by the personal genomics offerings of deCODE and Navigenics, which both provide direct-to-consumer reports of risk factors for 20-30 common diseases, such as asthma, breast cancer, and diabetes. In the case of deCODE's US $\$ 985$ deCODEme product, calculation of an individual's risk factors depends directly on deCODE's proprietary access to a national biobank, whereas Navigenics calculates the risk factors in its US $\$ 2500$ Health Compass on the basis of gene-disease connections found in published literature (some of which is based on large-scale biobank resources).

Both companies also offer subscription services that allow consumers to have their reports updated as new links between genes, environment, and diseases are discovered or new therapies become available.

Ontologizing risk also makes it possible to expand considerably the market for preventive drugs: that is, drugs that aim not to cure or alleviate a current disease state but instead prevent a future instance of a disease for which one is "at risk." By implicitly configuring the population as "the future ill," national biobanks enable an expansion of pharmaceutical markets by validating searches not just for therapies that alleviate or cure a disease with which an individual is currently afflicted but, in addition, compounds designed to prevent conditions for which one is at risk. deCODE is a clear instance of this logic, for in their Web press materials they list as their primary achievements to date the creation of "two compounds for the prevention of heart attack and an antiplatelet compound for the prevention of arterial thrombosis, as well as DNAbased diagnostic tests to predict risk of type 2 diabetes, heart attack, atrial fibrillation/stroke, and prostate and breast cancer." Although the identification of some genetically-linked risk factors could in principle lead to noncommercial interventions, such as changes in diet or exercise, deCODE's description emphasizes the extent to which the maintenance of "health" tends to be understood in terms of pharmaceutical interventions.

\section{Conclusion}

From our perspective, analyses of the bioethics and citizenship aspects of national biobanks risk missing a crucial dimension, namely, the economic logic of the mediations between states, national populations, and commercial entities that national biobanks enable. As we have demonstrated, biobanks enroll significant sections of national populations as economically productive participants, subjects who lend their bodies and prospective medical histories to create a research resource with significant commercial potential. Although they participate under a rubric of citizenship and public good, their participation is nevertheless formulated in profitable ways. Our shift from the civil discourse of participation to the economic discourse of labor clarifies the commercial logics at work in the creation of national biobanks and raises new and important questions about equity, the rights of research donors, and the social distribution of research benefits. These questions are thrown into even sharper focus by our identification of risk expansion, and hence pharmaceutical market expansion as a corollary of biobank research.

At a conceptual level, our emphasis on the economic logic of national biobanks points to the need for a more general theory of value and labor for the post genomic era. As we have noted above, national biobanks enable a new form of biovalue creation, one that operates in a significantly different way than in the cases of, for example, clinical trials, cell lines, and reproductive services such as oocyte vending. Where the latter tend to separate individuals from the biovalue that is created, national biobanks depend on the persistence of linkages between individuals - now grouped into "populations"- and technologies of biovalue creation. Yet these two modalities of biovalue are by no means disjunctive; for the emergence 
of the "collective" mode of biovalue creation associated with national biobanks in fact establishes new fields for older forms of biovalue creation. National biobanks, for example, are not intended to replace clinical trials but instead are designed to enable many new clinical trials that will follow from the isolation of diagnostic possibilities and therapeutic compounds. Rather than "displacing" an older with a newer mode of biovalue creation, national biobanks extend and deepen the field of operation in which biovalue can be created.

Our analysis also emphasizes in striking ways the extent to which this new dynamic of biovalue creation depends on the phenomenon of "surplus health" described by Dumit. As Dumit has noted, the emergence of an autonomous health industry establishes a potential structural problem for capitalism: insofar as the growth of the health industry depends on "people becoming more sick," its growth seems to be in tension with the growth of other sectors of the economy. The solution to this structural problem is the creation of "surplus health," or that "proportion of health unnecessary for maintaining one's capacity as a worker" (Dumit 2004). Preventive medicine is especially well suited for the creation of surplus health, for by enabling the diagnostic identification, and pharmaceutical management, of "risk factors" for diseases, rather than simply the diseases themselves, it becomes possible to expand markets for diagnostics and medication, without at the same time reducing an individual's capacity for labor. National biobanks are especially well suited to the identification of those kinds of risk factors that — because they are tied in part to genomic profiles — can be linked to diagnostics and medication. Thus, precisely because they mediate between states, commercial entities, and the health of both individuals and national populations, national biobanks highlight one component of the "exceptional" nature of neoliberalism, as it allows the national health care systems of former welfare states to be "repurposed" for new ends.

\section{Acknowledgments}

The authors gratefully acknowledge the help of Robert Cook-Deegan, Misha Angrist, and the editors and anonymous reviewers of ST\&HV for their helpful comments on earlier drafts of this essay, and Jenny Rhee for help with references and proofreading.

\section{Biographies}

Robert Mitchell is an associate professor in the Department of English, a Faculty member in the Institute of Genome Sciences and Policy, and Affiliated Faculty with Women's Studies at Duke University. His recent publications include Tissue Economies: Blood, Organs and Cell Lines in Late Capitalism (with Catherine Waldby, Duke University Press 2006) and the interactive DVD-ROM Biofutures: Owning Body Parts and Information (with Helen Burgess and Phillip Thurtle, University of Pennsylvania Press, 2008). His recent work has focused especially on U.S. biobanking projects.

Catherine Waldby is an associate professor and International Research Fellow in the Department of Sociology and Social Policy, Sydney University. Her recent books include Tissue Economies: Blood, Organs and Cell Lines in Late Capitalism (with Robert Mitchell, Duke University Press 2006) and The Global Politics of Human Embryonic Stem Cell Science: Regenerative Medicine in Transition, (with Herbert Gottweis and Brian Salter, Palgrave 2009). She has received national and international research grants for her work on embryonic stem cells, blood donation and biobanking.

\section{References}

Anon. UK Biobank: Protocol for a large-scale prospective epidemiological resource. 2006. www.ukbiobank.ac.uk/docs/UKBProtocol_000.pdf. Accessed September 27, 2008 
Austin M, Harding S, McElroy C. Monitoring ethical, legal, and social issues in 3 developing population genetic databases. Genetics in Medicine 2003;5(6):451-7. [PubMed: 14614397]

Bazell, R. Her-2: The making of herceptin, a revolutionary treatment for breast cancer. Random House; New York: 1998.

Busby H, Martin P. Biobanks, national identity and imagined communities: The case of UK biobank. Science as Culture 2006;15(3):237-51.

Cambon-Thomsen A, Ducournau P, Gourraud P-A, Pontille D. Biobanks for genomics and genomics for biobanks. Comparative and Functional Genomics 2003;4(6):628-34. [PubMed: 18629026]

Clayton DG, McKeigue PM. Epidemiological methods for studying genes and environmental factors in complex diseases. Lancet 2001;358(9290):1356-60. [PubMed: 11684236]

Collins F. The case for a US prospective cohort study of genes and environments. Nature 2004;429(6990): 475-9. [PubMed: 15164074]

Collins F. Necessary but not sufficient. Nature 2007;445(7125):259. [PubMed: 17230172]

Cooper M. Experimental labour: Offshoring clinical trials to china. East Asian Science, Technology and Society: An International Journal 2008;2(1):73-92.

Corrigan, O. Bioethics: Managing risks in UK biobank. Biobank Governance in Comparative Perspective. University of Vienna; 2006.

Davies, G. The Independent. London: Jan 15. 1996 Tony Blair puts meat on the stakeholder bones.

Decamp M, Sugarman J. Ethics in population-based genetic research. Accountability in Research 2004;11 (1):1-26. [PubMed: 15341044]

Dumit, J. Drugs, algorithms, markets and surplus health; Workshop paper presented at the Department of Anthropology; Irvine: University of California; 2004.

Eiseman, E.; Haga, SB. Handbook of human tissue sources: A national resource of human tissue samples. RAND Corporation; Santa Monica, CA: 1999.

Freeman, RE. Strategic management: A stakeholder approach. Pitman Publishing; Boston: 1984.

Friede, A.; Grossman, R.; Hunt, R.; Li, RM.; Stern, S., editors. National biospecimen network blueprint. Constella Group Inc.; Durham, NC: 2003.

Fuji-Keizai U.S.A. U.S. DNA-based diagnostic and test market. Fuji-Keizai U.S.A. Inc.; New York: 2008.

Gibbons S, Kaye J, Smart A, Heeney C, Parker M. Governing genetic databases: Challenges facing research regulation and practice. Journal of Law and Society 2007;4(2):163-89.

Hoeyer, K. Ambiguous gifts: Public anxiety, informed consent and biobanks. In: Tutton, R.; Corrigan, O., editors. Genetic Databases: Socio-ethical issues in the collection and use of DNA. Routledge; London and New York: 2004. p. 97-116.

Hutton, W.; Goldblatt, D. The stakeholding society: Writings on politics and economics. Polity Press, Blackwell Publishers; Cambridge, Malden, MA: 1999.

Hyman SE. The needs for database research and for privacy collide. American Journal of Psychiatry 1999;157(11):1723-4. [PubMed: 11058462]

Kaiser J. Population databases boom, from Iceland to the U.S. Science 2002;298(5596):1158. [PubMed: 12424349]

Kaye, J. Abandoning informed consent: The case of genetic research in population collections. In: Tutton, R.; Corrigan, O., editors. Genetic databases: Socio-ethical issues in the collection and use of DNA. Routledge; London and New York: 2004. p. 117-38.

Khoury MJ, Yang Q, Gwinn M, Little J, Dana FW. An epidemiologic assessment of genomic profiling for measuring susceptibility to common diseases and targeting interventions. Genetics in Medicine 2004;6(1):38-47. [PubMed: 14726808]

Levitt M, Weldon S. A well placed trust? Public perceptions of the governance of DNA databases. Critical Public Health 2005;15(4):311-21.

Levy, D.; Brink, S. A change of heart: How the Framingham heart study helped unravel the mysteries of cardiovascular disease. Alfred A. Knopf; New York: 2005.

Lewis, G. Tissue collection and the pharmaceutical industry: investigating corporate biobanks. In: Tutton, R.; Corrigan, O., editors. Genetic databases: Socio-ethical issues in the collection and use of DNA. Routledge; London and New York: 2004. p. 181-201. 
Nahman, M. Israeli extraction: An ethnographic study of egg donation and national imaginaries. Lancaster University; UK: 2005.

OECD. The bioeconomy to 2030: Designing a policy agenda. OECD; Paris: 2006.

Ong, A. Neoliberalism as exception: Mutations in citizenship and sovereignty. Duke University Press; Durham and London: 2006.

Parry, B. Trading the genome: Investigating the commodification of bio-information. Columbia University Press; New York: 2004.

Petersen A. Securing our genetic health: engendering trust in UK Biobank. Sociology of Health and Illness 2005;27(2):271-92. [PubMed: 15787778]

Rajan, KS. Biocapital: The constitution of postgenomic life. Duke University Press; Durham: 2006.

Rose, H. The commodification of bioinformation: The Icelandic health sector database. Wellcome Trust; London: 2001.

Rose H. From hype to mothballs in four years: troubles in the development of large-scale DNA biobanks in Europe. Community Genetics 2006;9(3):184-9. [PubMed: 16741348]

Rothstein, WG. Public health and the risk factor: A history of an uneven medical revolution. University of Rochester Press; New York: 2003.

Salter B, Jones M. Biobanks and bioethics: the politics of legitimation. Journal of European Public Policy 2005;12(4):710-32.

Slamon DJ, Godolphin W, Jones LA, Holt JA, Wong SG, Keith DE, Levin WJ, Stuart SG, Udove J, Ullrich A, et al. Studies of the HER-2/neu proto-oncogene in human breast and ovarian cancer. Science 1989;244(4905):707-12. [PubMed: 2470152]

Smith GD, Ebrahim S, Lewis S, Hansell AL, Palmer LJ, Burton PR. Genetic epidemiology and public health: Hope, hype, and future prospects. Lancet 2005;366(9495):1484-98. [PubMed: 16243094]

Taylor C. Consumer privacy and the market for customer information. RAND Journal of Economics 2004;35(4):631-50.

Terwilliger JD, Göring HHH. Gene mapping in the 20th and 21st centuries: Statistical methods, data analysis, and experimental design. Human Biology 2002;72(1):63-132.

Tutton R. Constructing participation in genetic databases: Citizenship, governance and ambivalence. Science, Technology and Human Values 2007;32(2):172-95.

Vandenbroucke JP, Koster T, Briet E, Reitsma P, Bertina R, Rosendaal F. Increased risk of venous thrombosis in oral-contraceptive users who are carriers of factor V Leiden mutation. Lancet 1994;344 (8935):1453-57. [PubMed: 7968118]

Waldby C. Stem cells, tissue cultures and the production of biovalue. Health: An Interdisciplinary Journal for the Social Study of Health, Illness and Medicine 2002;6(3):305-23.

Waldby C. Oocyte markets: Women's reproductive labour in embryonic stem cell research. New Genetics and Society 2008;27(1):19-31.

Waldby C, Cooper M. The biopolitics of reproduction: Post-Fordist biotechnology and women's clinical labour. Australian Feminist Studies 2008;23(2):57-73.

Waldby, C.; Mitchell, R. Tissue economies: Blood, organs and cell lines in late capitalism. Duke University Press; Durham: 2006. 